\title{
Cerebral Hemodynamics at Altitude: Effects of Hyperventilation and Acclimatization on Cerebral Blood Flow and Oxygenation
}

\author{
Matthew R. Sanborn, MD; Mark E. Edsell, MB, ChB; Meeri N. Kim, MA; Rickson Mesquita, PhD; \\ Mary E. Putt, ScD; Chris Imray, MB, BS; Heng Yow, MB, ChB; Mark H. Wilson, MB, BChir; Arjun G. Yodh, PhD; \\ Mike Grocott, MB, ChB; Daniel S. Martin, MB, ChB \\ From the UCL Centre for Altitude, Space and Extreme Environment Medicine, Portex Unit, Institute of Child Health (Drs Sanborn, Edsell, \\ Imray, Yow, Wilson, Grocott, and Martin), and St. George's Hospital (Dr Edsell), London, UK; Maine Medical Center, Portland, ME \\ (Dr Sanborn); the University Hospitals Coventry and Warwickshire NHS Trust, Warwick Medical School, Coventry, UK (Dr Imray); and the \\ Departments of Physics and Astronomy (Drs Kim, Mesquita, and Yodh) and Biostatistics and Epidemiology (Dr Putt), University of \\ Pennsylvania, Philadelphia, PA.
}

\begin{abstract}
Objective.-Alterations in cerebral blood flow (CBF) and cerebral oxygenation are implicated in altitudeassociated diseases. We assessed the dynamic changes in $\mathrm{CBF}$ and peripheral and cerebral oxygenation engendered by ascent to altitude with partial acclimatization and hyperventilation using a combination of near-infrared spectroscopy, transcranial Doppler ultrasound, and diffuse correlation spectroscopy.

Methods.-Peripheral $\left(\mathrm{SpO}_{2}\right)$ and cerebral $\left(\mathrm{SctO}_{2}\right)$ oxygenation, end-tidal carbon dioxide $\left(\mathrm{ETCO}_{2}\right)$, and cerebral hemodynamics were studied in 12 subjects using transcranial Doppler and diffuse correlation spectroscopy (DCS) at $75 \mathrm{~m}$ and then 2 days and 7 days after ascending to $4559 \mathrm{~m}$ above sea level. After obtaining baseline measurements, subjects hyperventilated to reduce baseline $\mathrm{ETCO}_{2}$ by $50 \%$, and a further set of measurements were obtained.

Results.-Cerebral oxygenation and peripheral oxygenation showed a divergent response, with cerebral oxygenation decreasing at day 2 and decreasing further at day 7 at altitude, whereas peripheral oxygenation decreased on day 2 before partially rebounding on day 7. Cerebral oxygenation decreased after hyperventilation at sea level $\left(\mathrm{Scto}_{2}\right.$ from $68.8 \%$ to $63.5 \% ; P<.001$ ), increased after hyperventilation after 2 days at altitude $\left(\mathrm{Scto}_{2}\right.$ from $65.6 \%$ to $\left.69.9 \% ; P=.001\right)$, and did not change after hyperventilation after 7 days at altitude $\left(\operatorname{Scto}_{2}\right.$ from $62.2 \%$ to $\left.63.3 \% ; P=.35\right)$.

Conclusions.-An intensification of the normal cerebral hypocapnic vasoconstrictive response occurred after partial acclimatization in the setting of divergent peripheral and cerebral oxygenation. This may help explain why hyperventilation fails to improve cerebral oxygenation after partial acclimatization as it does after initial ascent. The use of DCS is feasible at altitude and provides a direct measure of $\mathrm{CBF}$ indices with high temporal resolution.
\end{abstract}

Key words: hypoxia, cerebral oxygenation, altitude

\section{Introduction}

Acute exposure to high altitude hypoxia can cause pathophysiological changes that manifest as a spectrum of disorders ranging from the relatively benign high altitude headache to life-threatening high altitude cerebral edema. Although these changes seem to be related to cerebral

Drs Edsell and Sanborn contributed equally to this study.

Corresponding author: Matthew R. Sanborn, MD, Maine Medical Partners Neurosurgery and Spine, 49 Spring Street, Scarborough, ME 04074 (e-mail: matthewrsanborn@gmail.com). hypoxemia, ${ }^{1}$ the underlying pathophysiology remains elusive with the cerebrovascular response to altitude incompletely characterized. Cerebral oxygenation is determined by arterial oxygen content, oxygen consumption, and cerebral blood flow (CBF). In turn, $\mathrm{CBF}$ is subject to different regulatory mechanisms than peripheral blood flow and is known to be particularly reactive to changes in arterial carbon dioxide.

Studies of cerebral hemodynamics at altitude have been hampered by the lack of an effective method to monitor intracranial blood flow. Diffuse correlation 
spectroscopy (DCS) is a novel technology that provides a noninvasive, portable estimation of changes in cortical blood flow. It measures the optical phase shifts caused by moving blood cells using near-infrared light. Importantly, it does not rely on the principles of tracer clearance. ${ }^{2}$ Currently, this technology is able to measure relative changes in cerebral blood flow (rCBF) in response to an intervention in the acute setting, but not absolute changes over long periods.

Using this new technology in conjunction with nearinfrared spectroscopy (NIRS) to measure cerebral oxygenation and transcranial Doppler (TCD) measurements of blood flow velocity in the middle cerebral artery, we sought to elucidate the effects of acclimatization and hyperventilation on a cohort of climbers ascending to $4559 \mathrm{~m}$ and to study the relationship between peripheral oxygenation $\left(\mathrm{SpO}_{2}\right)$, cerebral oxygenation $\left(\mathrm{Scto}_{2}\right)$, endtidal $\mathrm{CO}_{2}\left(\mathrm{ETCO}_{2}\right)$, and $\mathrm{CBF}$.

\section{Methods}

\section{SUBJECTS AND SETTING}

Approval for this study was obtained from the ethics committees of the University of Turin and University College London. All participants underwent medical screening, and written informed consent was obtained after the possible risks of the study were explained.

Twelve subjects ranging in age from 22 to 80 years, with varying degrees of experience at altitude and residing at or below $75 \mathrm{~m}$ above sea level, were recruited from the 2010 Xtreme Alps Medical Research Expedition. None had traveled to altitude during the previous 3 months. Subjects were studied at $75 \mathrm{~m}$ above sea level before the expedition. Subjects then ascended by cable car and foot to $3611 \mathrm{~m}$ where they acclimatized for 2 days before ascending by foot to the Capanna Regina Margherita at $4559 \mathrm{~m}$. Two further sets of measurements were taken 2 days and 7 days after arriving at the Capanna Regina Margherita.

\section{EXCLUSIONS}

Subjects with symptoms of acute mountain sickness (AMS) severe enough to require treatment with dexamethasone or acetazolamide were excluded from further participation in the study after they began treatment.

\section{MEASUREMENTS}

Each subject was positioned supine and allowed to rest for 5 minutes. Baseline measurements of CBF were obtained using both DCS and TCD ultrasound (Table). Subjects were then instructed to hyperventilate while undergoing $\mathrm{ETCO}_{2}$ monitoring with a tight-fitting facemask with in-line capnometry (EMMA Capnometer, Phasein Medical Technologies, Danderyd, Sweden) and given feedback regarding depth and rate of respiration needed to reach the target $\mathrm{ETCO}_{2}$ of $50 \%$ of baseline.

After achieving and maintaining this target $\mathrm{ETCO}_{2}$ for 3 minutes, an additional set of measurements were obtained and averaged. Peripheral arterial oxygen saturation was recorded by a near-infrared pulse oximetry probe (Onyx model 9500, Nonin Medical, Plymouth, $\mathrm{MN})$.

\section{NEAR-INFRARED SPECTROSCOPY}

The Fore-Sight Absolute Cerebral Oximeter (CAS Medical Systems, Inc, Branford, CT) was used to measure the oxygen saturation of cerebral tissue. This is an "absolute cerebral oximeter" using fiberoptic laser light

Table. Resting physiology at sea level and on study days at $4559 \mathrm{~m}^{a}$

\begin{tabular}{lccc}
\hline \multicolumn{1}{c}{ Altitude } & $150 \mathrm{~m}$ & Day 2 at $4559 \mathrm{~m}$ & Day 7 at $4559 \mathrm{~m}$ \\
\hline $\mathrm{SpO}_{2}(\%)$ & $98 \pm 0.42$ & $81.2 \pm 1.42$ & $85.9 \pm 1.47$ \\
$\mathrm{SctO}_{2}(\%)$ & $68.8 \pm 1.21$ & $65.4 \pm 2.01$ & $62.4 \pm 1.75$ \\
$\mathrm{DCS}, \%$ with HV & $20.9 \pm 3.8$ & $24.5 \pm 5.9$ & $37.4 \pm 8.2$ \\
$\mathrm{TCD}, \%$ with HV & $33 \pm 3.7$ & $31.7 \pm 7.3$ & $31.5 \pm 3.1$ \\
$\mathrm{HR}$ (beats/min) & $64 \pm 4.1$ & $81 \pm 6.4$ & $80 \pm 6.25$ \\
$\mathrm{RR}($ breaths/min) & $14 \pm 1.3$ & $16 \pm 1.7$ & $14 \pm 1.1$ \\
$\mathrm{SBP}(\mathrm{mm} \mathrm{Hg})$ & $110 \pm 3.4$ & $118 \pm 4.4$ & $127 \pm 7.1$ \\
DBP (mm Hg) & $70 \pm 2.0$ & $77 \pm 2.9$ & $83 \pm 4.6$ \\
Resting ETCO & $(\mathrm{kPa})$ & $3.39 \pm 0.14$ & $3.09 \pm 0.15$ \\
Lake Louise Score & $4.5 \pm 0.2$ & $3.7 \pm 1.5$ & $0.7 \pm 0.4$ \\
\hline
\end{tabular}

\footnotetext{
${ }^{a}$ Values are reported as mean \pm SEM.

DBP, diastolic blood pressure; DCS, diffuse correlation spectroscopy; $\mathrm{ETCO}_{2}$, end-tidal carbon dioxide; HR, heart rate; HV, hyperventilation; RR, respiration rate; $\mathrm{SBP}$, systolic blood pressure; $\mathrm{Scto}_{2}$, cerebral oxygen saturation; $\mathrm{SpO}_{2}$, peripheral oxygen saturation; $\mathrm{TCD}$, transcranial Doppler.
} 
of 4 different wavelengths to measure tissue oxygenation. It has been shown to be less affected by changes in ambient light and obviates the need for baseline calibration. ${ }^{3-5}$ NIRS probes were placed $1.5 \mathrm{~cm}$ above the brow overlying the right hemisphere with care being taken to avoid the frontal sinus and the superior sagittal sinus. A wool cap was then placed over the probe to minimize interference from ambient light and to apply a constant even pressure. Baseline measurements of $\mathrm{SpO}_{2}$ and $\mathrm{Scto}_{2}$ were obtained every 60 seconds for a total of 3 minutes and averaged.

\section{DIFFUSE CORRELATION SPECTROSCOPY}

Diffuse correlation spectroscopy uses near-infrared light of discrete wavelengths coupled to a detector. The decay rate of the detected light intensity autocorrelation function $\left(\mathrm{g}_{2}\right)$ is used to calculate changes in $\mathrm{CBF}^{6-8}$ DCS has been shown to reflect changes in CBF in adult humans $s^{9,10}$ and neonates ${ }^{11}$ and has been validated against arterial spin-labeled magnetic resonance imaging (MRI) in rodents. ${ }^{12}$ DCS has also been validated against xenon-enhanced computed tomography, ${ }^{13}$ phase-encoded velocity mapping MRI, ${ }^{14}$ and fluorescent microspheres. ${ }^{15}$

The optical probes for DCS used 2 laser sources of near-infrared light $(785 \mathrm{~nm}$ and $830 \mathrm{~nm})$ separated by $2.5 \mathrm{~cm}$ from single-photon counting avalanche photodiodes for detection. The data were recorded and averaged over 3-second intervals. Motional dynamics (ie, flow) are measured using the time dependence of detected diffuse light intensity and computing the intensity autocorrelation function assuming Brownian diffusion dynamics. ${ }^{2}$ Probes were placed securely against the left forehead, avoiding both the superior sagittal sinus and the frontal sinus. A single operator (M.S.) performed all DCS measurements, and data extraction and interpretation was blinded and performed by a separate team member (M.K.).

\section{TRANSCRANIAL DOPPLER}

Transcranial Doppler was assessed using the Sonosite MicroMaxx, (Sonosite, Bothell, WA) handheld ultrasound using a previously published technique. ${ }^{16}$ A P21x/ 5-1 MHz transducer was used to insonate the middle cerebral artery (MCA) via the right temporal window. The clinoid process of the sphenoid bone, the circle of Willis, and the distal internal carotid artery were initially identified, and then the M1 segment of the MCA was identified (characterized by flow toward the transducer). An optimal portion of the MCA without branches and with laminar flow was then selected and the depth recorded. Once identified, the center of the artery was insonated, and Doppler ultrasonography was performed to measure MCA blood velocity $\left(\mathrm{MCA}_{\mathrm{Vel}}\right)$, peak systolic velocity (PSV), and end-diastolic velocity (EDV). The pulsatility index (PI), and resistivity index (RI) were calculated by the manufacturer-provided software. On subsequent studies, every effort was made to insonate the same depth (to within $1 \mathrm{~mm}$ ). After 3 to 5 minutes of insonation, the 2-dimensional image movie sequence was saved, and the frame with the maximal vessel diameter (systole) studied. The angle of insonation was constant for each individual because the position of the probe on the temporal bone window and the position on the interrogated section of the MCA were fixed. The TCD measurements were performed by 2 experienced operators (M.E. and H.Y.). Three measurements were obtained at each time, and the average was used for further calculation.

\section{STATISTICAL METHODS}

Data are expressed as mean \pm SEM. To account for the correlation between repeated measurements on the same subject, we fit a mixed effects model and used the model to test each hypothesis. Specifically we used Wald tests to determine whether there was evidence of differences between means of the physiological parameters measured at each of the days at altitude vs sea level and at day 1 at altitude vs day 7 at altitude. We also estimated and tested for differences between the means of the physiological parameters before and after hyperventilation at sea level vs each day at altitude. The model was also used to generate estimates and 95\% CI for relevant parameters. Our primary analysis included all patients who contributed data at any time in the study; a secondary analysis included only those subjects who completed the study, contributing data at all 3 times. Correlation between $\mathrm{Scto}_{2}$ and $\mathrm{ETCO}_{2}$, or $\mathrm{Spo}_{2}$ was performed using Spearman's correlation. Statistical significance was defined as a probability value less than .05 . The R Project for Statistical Computing (www.r-project. org) and STATA 11.1 statistical software (StataCorp, College Station, TX) were used for statistical analysis.

\section{Results}

Of 12 initial subjects, data were collected on 9 subjects after 2 days at altitude and 7 subjects after 7 days at altitude. Incomplete data were a result of 2 subjects exhibiting AMS severe enough to require treatment with dexamethasone or acetazolamide before day 2 at altitude; these subjects contributed data only to the sea level measurements. Furthermore, 1 subject left the study before departure for altitude and 1 subject left after 4 days at altitude. One subject was unable to tolerate maximal hyperventilation on day 7 and was excluded; 
otherwise hyperventilation to a 50\% reduction in $\mathrm{ETCO}_{2}$ was achieved and maintained in all other subjects throughout the study period. For the primary data analysis, all subjects with usable data at any time were included in the study; a sensitivity analysis was carried out using only those subjects who had observations collected at each time.

\section{PERIPHERAL OXYGENATION}

Mean baseline peripheral oxygenation decreased from 98.0\% (95\% CI, 96.0 to 100.0 ) at sea level to $81.2 \%$ (95\% CI, 78.9 to $83.5 ; P<.0001$ ) at day 2 at $4559 \mathrm{~m}$. At day 7 at altitude, mean $\mathrm{Spo}_{2}$ was $85.9 \%$ (95\% CI, 83.2 to 88.5$)$, still significantly lower than sea level $(P<$ $.0001)$ but somewhat higher than at day $2(P=.013)$. Mean $\mathrm{SpO}_{2}$ remained unchanged at sea level after hyperventilation. After 2 days at $4559 \mathrm{~m}$, hyperventilation improved mean $\mathrm{Spo}_{2}$ by $15.3 \%$ to $95.9 \%$ (95\% CI, 92.6 to $99.3 ; P<.0001)$. After 7 days at $4559 \mathrm{~m}$, hyperventilation increased mean $\mathrm{Spo}_{2}$ by $10.0 \%$ to 95.9\% (95\% CI, 29.6 to $99.3 ; P<.0001$ ).

\section{CEREBRAL OXYGENATION}

As previously mentioned, peripheral oxygenation dropped initially at day 2 after ascent to altitude before modestly rebounding by 7 days at altitude. In contrast, cerebral oxygenation continued to decline throughout, decreasing from $68.8 \%(95 \% \mathrm{CI}, 65.7$ to 72.0$)$ at sea level to $65.6 \%$ (95\% CI, 62.1 to 69.0 ) after 2 days at altitude and further to $62.2 \%$ (95\% CI, 58.4 to 66.0 ) at day 7 (Figure 1). Differences in cerebral oxygenation reached significance only between sea level and day 2 at altitude $(P=.004)$.

After hyperventilation, cerebral oxygenation decreased from $68.8 \%$ (95\% CI, 65.7 to 72.0 ) to $63.5 \%$ (95\%

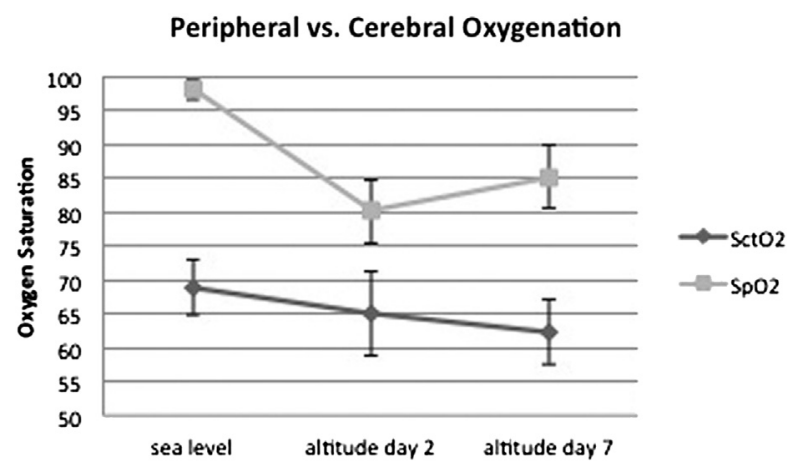

Figure 1. Changes in cerebral $\left(\mathrm{Scto}_{2}\right)$ and peripheral $\left(\mathrm{Spo}_{2}\right)$ oxygenation with acclimatization. Both peripheral and cerebral oxygenation decreased after 2 days at $4559 \mathrm{~m}$. After further acclimatization, peripheral oxygenation rebounded, whereas cerebral oxygenation continued to decline.
CI, 59.5 to $67.5 ; P<.001)$ at sea level. After 2 days at altitude, hyperventilation resulted in an increase in cerebral oxygenation from $65.6 \%(95 \% \mathrm{CI}, 62.1$ to $69.0)$ to $69.9 \%$ (95\% CI, 65.6 to $74.3 ; P=.001)$. After 7 days at altitude there was no significant difference between cerebral oxygenation before $(62.2 \%$; $95 \% \mathrm{CI}$, 58.4 to 66.0$)$ or after $(63.3 \% ; 95 \%$ CI, 58.5 to $68.2 ; P=$ $.35)$ hyperventilation. End-tidal $\mathrm{CO}_{2}$ decreased from 4.5 $\pm 0.8 \mathrm{kPa}$ at sea level to $3.4 \pm 0.4 \mathrm{kPa}$ after 2 days at altitude and to $3.2 \pm 0.4 \mathrm{kPa}$ after 7 days at altitude. Resting peripheral oxygenation was not correlated with cerebral oxygenation $(\rho=.355 ; P=.07)$, However, resting $\mathrm{ETCO}_{2}(\rho=.491 ; P<.01)$ was correlated with cerebral oxygenation $(\rho=.512 ; P=.006)$.

\section{CEREBRAL BLOOD FLOW}

Baseline (prehyperventilation) peak systolic velocity (PSV) increased significantly between sea level (82.4 $\mathrm{cm} / \mathrm{s})$ and day 2 at altitude $(97.3 \mathrm{~cm} / \mathrm{s} ; P=.007)$ and decreased between day $2(97.3 \mathrm{~cm} / \mathrm{s})$ and day 7 at altitude $(79.22 \mathrm{~cm} / \mathrm{s} ; P=.004)$. However there was no difference between sea level and day 7 at altitude $(P=.55)$. Sea level PSV was reduced from $82.4 \mathrm{~cm} / \mathrm{s}$ (95\% CI, 68.7 to 96$)$ to $54.1 \mathrm{~cm} / \mathrm{s}(95 \%$ CI, 44.3 to 63.8 ; $P<.001)$ after hyperventilation. At day 2 of altitude, baseline PSV had increased to $97.3 \mathrm{~cm} / \mathrm{s}(95 \% \mathrm{CI}, 82.8$ to 111.8$)$ and decreased to $64.0 \mathrm{~cm} / \mathrm{s}(95 \%$ CI, 53.3 to $74.5 ; P<.001)$ after hyperventilation. After 7 days at $4559 \mathrm{~m}, \mathrm{PSV}$ decreased from $79.22 \mathrm{~cm} / \mathrm{s}(95 \% \mathrm{CI}, 64.0$ to 94.4$)$ to $55.5 \mathrm{~cm} / \mathrm{s}(95 \% \mathrm{CI}, 44.1$ to $66.9 ; P<.001)$ after hyperventilation (Figure 2A).

DCS revealed a decrease in rCBF of $20.9 \%$ (95 CI, 31.3 to 10.3 ) after hyperventilation at sea level, $24.5 \%$ (95\% CI, 36.7 to 12.4 ) after hyperventilation after 2 days at altitude, and $37.6 \%$ (95\% CI, 51.3 to 23.8 ) after 7 days at altitude. There was a not significant trend toward greater hyperventilation-induced reductions in CBF with increasing times at altitude $(P=.051$ between sea level [20.9\%] and day 7 at altitude [37.6\%]; Figure 2B). As demonstrated in Figure 2, and with the wide 95\% CI at all times, there is considerable interindividual variability in both TCD and DCS measurements.

There was a poor correlation between percentage change of $\mathrm{rCBF}$ and percentage change of PSV with hyperventilation $(\rho=0.019 ; P=.92$; Figure 3$)$.

\section{Discussion}

We have reported the changing, dynamic relationship between $\mathrm{SpO}_{2}, \mathrm{SctO}_{2}$, and $\mathrm{CBF}$ that occurs with hyperventilation after ascent to altitude and after partial acclimatization in a small number of subjects. There are several novel findings in this study. First, we have 


\section{A \% Change MCA peak velocity with HV (TCD)}

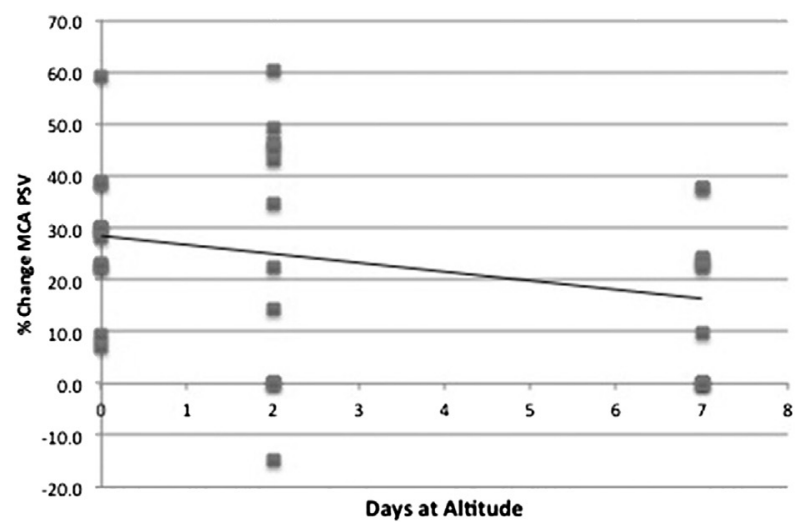

B

\% Change rCBF with HV (DCS)

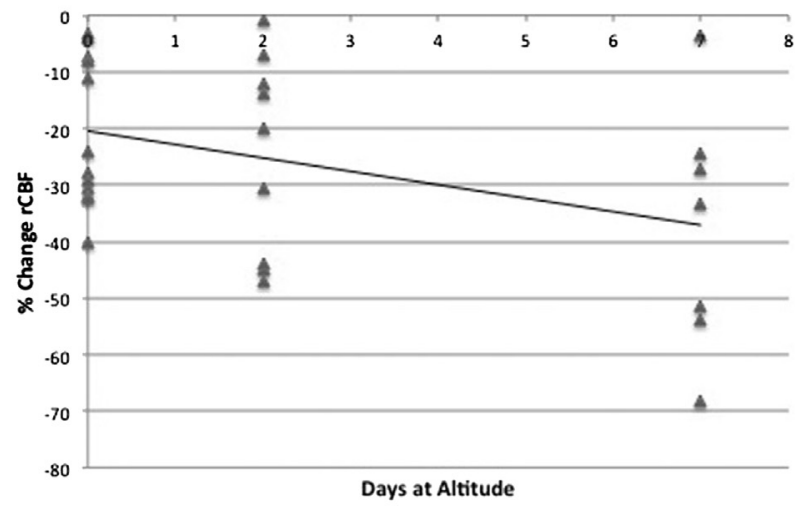

Figure 2. Scatter-plot demonstrating the percentage change induced by hyperventilation (HV) in peak systolic velocity (PSV) in the middle cerebral artery (MCA) measured by transcranial Doppler ultrasound (TCD; A) and percentage change in relative cerebral blood flow (rCBF) measured by diffuse correlation spectroscopy (DCS; B) at sea level (time 0) and on days 2 and 7 after arrival at $4559 \mathrm{~m}$.

demonstrated the feasibility of using DCS to measure cortical blood flow with a high temporal resolution in an austere environment. Second, we have demonstrated a differential effect of acclimatization on peripheral and cerebral oxygenation. Although both cerebral oxygenation and peripheral oxygenation decreased after 2 days at altitude, cerebral oxygenation continued to decrease at 7 days, whereas peripheral oxygenation had begun to rebound (Figure 1). Finally, using novel techniques, we have directly observed changing effects of voluntary hyperventilation on cerebral oxygenation and CBF with time in a small number of patients.

\section{CEREBRAL OXYGENATION}

Both cerebral oxygenation and peripheral oxygenation decreased after 2 days at altitude. At 7 days, however, cerebral oxygenation continued to decrease, whereas peripheral oxygenation had begun to rebound. This

\% Reduction in PSV and rCBF with Hyperventilation

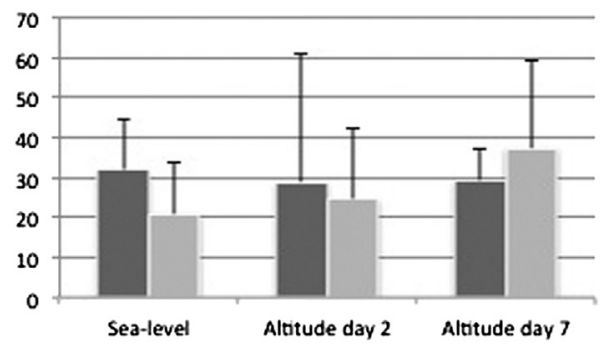

- PSV \% change D DCS $\%$ change

Figure 3. Percentage reduction in peak systolic velocity (PSV) measured by transcranial Doppler or relative cerebral blood flow (rCBF) measured by diffuse correlation spectroscopy (DCS) after hyperventilation to $50 \%$ of baseline end-tidal $\mathrm{CO}_{2}$. divergence of peripheral and cerebral oxygenation between days 2 and 7 highlights the fact that peripheral oxygenation is not a reliable predictor of cerebral oxygenation at altitude.

This divergence may be attributable to the differences in the vascular response to arterial $\mathrm{CO}_{2}$ between the periphery and the central nervous system. Interestingly, at simulated extreme altitudes, Hornbein et $\mathrm{al}^{17}$ found a significant correlation between subjects with a more pronounced hypoxic ventilatory response (HVR) and increased impairment on a variety of cognitive tasks. This contrasts with other reports demonstrating improved climbing performance in subjects with a higher HVR. ${ }^{18-20}$ This dichotomy between athletic and cognitive performance parallels the divergence between peripheral and cerebral oxygenation seen in the present study. Subjects with a more pronounced HVR are better able to increase peripheral oxygenation. ${ }^{21}$ However, this also results in hypocapnia, which leads to cerebral vasoconstriction, potentially exacerbating cerebral hypoxia. Thus, those travelers to very high altitudes that are most adapted to deal with the physical rigors of altitude may be most susceptible to cerebral hypoxia and the associated structural and functional changes. This may seem initially counterintuitive; acetazolamide is effective in treating and preventing the cerebral effects of AMS while increasing ventilation. ${ }^{22}$ However, acetazolamide also results in cerebral vasodilation. ${ }^{23}$ It is unclear whether the clinical effects of acetazolamide are secondary to its effect in increasing ventilation or its additional known effect of producing cerebral vasodilation. The increase in hyperventilation, and thus hypocapnic vasoconstriction, may be more than offset by the cerebral vasodilatory effects. 
Several previous studies have examined cerebral oxygenation measured using NIRS at altitude. ${ }^{24,25}$ This study is the first of its kind to use the absolute cerebral oximeter in the assessment of cerebral oxygenation at altitude. Previous studies have relied on examining regional cerebral saturation trends, making direct comparisons with peripheral saturation difficult. Limited studies suggest that absolute oximetry may offer slight advantages in reproducibility compared with other methods of cerebral oximetry. ${ }^{26}$ However, the inherent weakness of cerebral NIRS technology remains. ${ }^{27}$ NIRS monitors measure the saturation of oxyhemoglobin and deoxyhemoglobin in all biological material beneath the probe (arterioles, capillaries, tissue, and veins) and assumes a stable ratio of arterial to venous compartment volumes. Therefore, relative changes in these compartment volumes could also lead to changes in $\mathrm{Scto}_{2} \cdot{ }^{28}$ This is particularly relevant given the putative role of venous hypertension in the pathogenesis of AMS/high altitude cerebral edema. ${ }^{29-31}$

\section{HYPERVENTILATION AT ALTITUDE}

This study confirms that hyperventilation at sea level leads to a decrease in $\mathrm{Scto}_{2}$ in the presence of unchanged $\mathrm{SpO}_{2}$, likely as a result of hypocapnic vasoconstriction and the resultant decrease in CBF. In contrast, on day 2 at $4559 \mathrm{~m}$, both $\mathrm{Spo}_{2}$ and $\mathrm{Scto}_{2}$ returned to sea level values with acute hyperventilation to $50 \%$ of the baseline $\mathrm{ETCO}_{2}$. In the nonacclimatized subject, the normalization of peripheral oxygenation probably overcomes the negative effects of hypocapnic cerebral vasoconstriction to increase $\mathrm{Scto}_{2}$. The situation after acclimatization, however, is harder to explain. After voluntary hyperventilation on day 7 at altitude, $\mathrm{Spo}_{2}$ again returned to sea level values, whereas $\mathrm{Scto}_{2}$ did not. Thus, acclimatization abolished the initial improvement in cerebral oxygenation seen with hyperventilation.

These findings expand on the work of Imray et al, ${ }^{32}$ who demonstrated improved cerebral oxygenation after maximal hyperventilation for a period of 60 seconds after acute exposure to an altitude of $4680 \mathrm{~m}$. At altitudes lower than $4680 \mathrm{~m}$, however, hyperventilation decreased cerebral oxygenation.

These differences may reflect a shifting balance between hypocapnic cerebral vasoconstriction and improved peripheral oxygen saturation resulting from hyperventilation. Lucas et $\mathrm{al}^{33}$ found that the cerebral hemodynamic response to hypocapnia-that is, the percentage change in MCA velocity per $\mathrm{mm} \mathrm{Hg}$ change in $\mathrm{ETCO}_{2}$ - was enhanced 2 to 4 days after arrival to altitude and remained increased up to 2 weeks. This suggests that there may be a greater degree of vasoconstriction at altitude for any given change in arterial $\mathrm{CO}_{2}$ levels, although larger studies are necessary to confirm this effect.

\section{CEREBRAL BLOOD FLOW}

The ideal measurement of CBF at altitude would provide a real-time, noninvasive, portable absolute quantification of flow. Although various techniques have been used to approximate $\mathrm{CBF}$ at altitude, all have important shortcomings. ${ }^{34}$

Kety and Schmidt ${ }^{35}$ provided the first measurements of $\mathrm{CBF}$ in man using inhaled nitrous oxide and measurement of $\mathrm{N}_{2} \mathrm{O}$ concentrations in arterial and venous blood. Severinghaus ${ }^{36}$ applied this technique at altitude, demonstrating an initial increase in CBF of $24 \%$ 6 to 12 hours after ascent, declining to $13 \%$ above baseline after 3 to 5 days of acclimatization. Use of the Kety-Schmidt method requires that CBF be at a steady state; it is not an appropriate test for dynamic studies as the temporal resolution is poor. A fundamental assumption of the Kety-Schmidt method is that both jugular veins drain equal amounts of blood from homogeneous areas of the brain. In fact, the 2 jugular veins do not drain symmetric areas of the brain. ${ }^{37}$ In more than $60 \%$ of the population, 1 jugular vein is more than twice the size of the contralateral vein. ${ }^{38}$

CBF can also be measured using inhalation or injection of the radioisotope ${ }^{133} \mathrm{Xe}$. The Fick principle, which is also the basis for the Kety-Schmidt technique, is used to determine $\mathrm{CBF}^{39}$ This technique is complicated by the need to account for arterial recirculation of the xenon, ${ }^{40,41}$ as well as contamination from extracranial sources, such as the highly vascular scalp.

Transcranial Doppler ultrasound is currently the most common method for estimating CBF at altitude. TCD approximates blood flow to the brain by measuring velocity through one of the large arteries in the brain, typically the MCA. The accuracy of this measurement is predicated on the assumption that MCA diameter remains constant at altitude and assumes no regional variation. If there are changes in MCA diameter, then an increase in measured peak-systolic velocity may reflect either a decrease in MCA diameter and thus a net decrease of flow or an increase in diameter of smaller arteries and arterioles downstream from the MCA and thus a net increase in CBF. Although several studies have demonstrated that MCA diameter changes less than smaller intracranial vessels with small, acute changes in blood pressure or $\mathrm{CO}_{2},{ }^{42,43}$ a more recent study demonstrated that MCA diameter changes significantly with altitude. ${ }^{16}$ More recently, it has been shown that intact or 
partially intact cerebral vascular responses to carbon dioxide are associated with poor correlation between TCD MCA velocity and CBF. ${ }^{44}$

DCS demonstrated a consistent reduction in relative CBF after hyperventilation at all times. As previously mentioned, there was a trend toward a more robust decrease in $\mathrm{rCBF}$ with hyperventilation with increasing time at altitude that approached but did not achieve significance $(P=0.51)$. This potential exaggeration of the hypocapnic vasoconstrictive response with increasing time at altitude is in agreement with the findings of Lucas et al. ${ }^{33}$ It also may explain why the initial improvement in cerebral oxygenation with hyperventilation is abolished with increasing time at altitude, as the progressive increase in the cerebrovascular response to hypocapnia overcomes the increase in arterial oxygenation.

Although DCS signals consistently demonstrated the expected reduction in $\mathrm{rCBF}$ after hyperventilation, there was considerable interindividual variation. This variation may reflect physiological differences in acclimatization. Alternatively, it could reflect varying degrees of functional activation of the underlying cortex. CBF, as measured by DCS, has been shown to change with activation of the underlying motor cortex in a fingertapping task. ${ }^{45}$

Currently, absolute quantitative changes of CBF with DCS are difficult to obtain, and thus rCBF (blood flow changes relative to a baseline period) are typically measured. Obtaining absolute quantitative measurements is an active area of research.

There was poor correlation between changes in CBF measured by TCD and DCS. Although both TCD and DCS purport to measure changes in $\mathrm{CBF}$, they differ considerably in what, precisely, they are measuring, and thus this lack of correlation is not surprising. TCD measures flow velocity through the MCA and thus is a global indicator of changes in flow dynamics, reflecting changes to a large region of the concerned hemisphere and measuring velocity of flow rather than flow. It is thus susceptible to misinterpretation when the diameter of the measured vessel changes. DCS measures cortical perfusion and reflects changes in a focal region of brain parenchyma.

\section{Conclusions}

Regulation of $\mathrm{CBF}$ and oxygenation at altitude are dynamic processes reflecting a shifting balance between hypoxic vasodilation and hypocapnic vasoconstriction. The relative influence of these processes differs in the peripheral and cerebral circulations. Cerebrovascular reactivity to hypocapnia appears to increase with increasing time at altitude, although it did not reach statistical significance in our small cohort.

DCS is a promising technology with the potential to increase our understanding of changes in $\mathrm{CBF}$ at altitude. Larger studies and further refinements in technique are necessary to reduce intersubject variability.

\section{Acknowledgments}

Funding for this project came from The Wilderness Medical Society Hultgren Grant and American Alpine Club Research Grants to Dr Sanborn and for biostatistical support through NICHD P30 HD026979.

\section{Appendix}

\section{XTREME ALPS RESEARCH GROUP}

Tom Adams, Lindsay Biseker, Adam Booth, Oliver Burdall, Alexandra Cobb, Andrew Cumpstey, Steve Dauncey, Mark Edsell, James Farrant, Martin Feelisch, Bernadette Fernandez, Oliver Firth, Edward Gilbert, Daniel Grant, Michael Grocott, Phil Hennis, Laura Jackson, Will Jenner, Jildou van der Kaaij, Maryam Khosravi, Edith Kortekaas, Denny Levett, Zeyn Mahomed, Daniel Martin, Paula Meale, Jim Milledge, Kay Mitchell, Damian Mole, Oliver Moses, Michael Mythen, Fabio Rigat, Alasdair O'Doherty, Alex Salam, Matt Sanborn, Adam Sheperdigian, Fiona Shrubb, Jo Simpson, Nick Talbot, Liesel Wandrag, Savini Wijesingha, Wilby Williamson, Tom Woolley, Heng Yow.

Unrestricted grant support was provided by Deltex Medical and Smiths Medical. Mike Grocott leads the Xtreme-Everest oxygen research consortium which has received unrestricted grant funding from BOC Medical (Linde Group), Ely-Lilly Critical Care, Smiths Medical, Deltex Medical, London Clinic, and Rolex. All funds were paid directly to the home institutions of researchers within the consortium. Mike Grocott has also received honoraria for speaking (not related to this review) and/or travel expenses from Baxter, Fresenius-Kabi, BOC Medical (Linde Group), and Ely-Lilly Critical Care.

\section{References}

1. Vuyk J, Van Den Bos J, Terhell K, et al. Acetazolamide improves cerebral oxygenation during exercise at high altitude. High Alt Med Biol. 2006;7:290-301.

2. Cheung C, Culver JP, Takahashi K, Greenberg JH, Yodh AG. In vivo cerebrovascular measurement combining diffuse near-infrared absorption and correlation spectroscopies. Phys Med Biol. 2001;46:2053-2065.

3. Zaouter $\mathrm{C}$, Arbeid E. Influence of ambient light on cerebral oximeters. Br J Anaesth. 2010;105:873-874. 
4. MacLeod DB, Ikeda K, Vacchiano C, Lobbestael A, Wahr JA, Shaw AD. Development and validation of a cerebral oximeter capable of absolute accuracy. J Cardiothorac Vasc Anesth. 2012;26:1007-1014.

5. Hallacoglu B, Sassaroli A, Fantini S, Troen AM. Cerebral perfusion and oxygenation are impaired by folate deficiency in rat: absolute measurements with noninvasive near-infrared spectroscopy. J Cereb Blood Flow Metab. 2011;31:1482-1492.

6. Boas DA, Campbell LE, Yodh AG. Scattering and imaging with diffusing temporal field correlations. Phys Rev Lett. 1995;75:1855-1858.

7. Pine DJ, Weitz DA, Chaikin PM, Herbolzheimer E. Diffusing wave spectroscopy. Phys Rev Lett. 1988;60: 1134-1137.

8. Gagnon L, Desjardins M, Jehanne-Lacasse J, Bherer L, Lesage F. Investigation of diffuse correlation spectroscopy in multi-layered media including the human head. Opt Express. 2008;16:15514-15530.

9. Li J, Dietsche G, Iftime D, et al. Noninvasive detection of functional brain activity with near-infrared diffusing-wave spectroscopy. J Biomed Opt. 2005;10:44002.

10. Favilla CG, Mesquita RC, Mullen M, et al. Optical bedside monitoring of cerebral blood flow in acute ischemic stroke patients during head-of-bed manipulation. Stroke. 2014;45:1269-1274.

11. Roche-Labarbe N, Carp SA, Surova A, et al. Noninvasive optical measures of $\mathrm{CBV}, \mathrm{StO}(2), \mathrm{CBF}$ index, and rCMRO (2) in human premature neonates' brains in the first six weeks of life. Hum Brain Mapp. 2010;31:341-352.

12. Carp SA, Dai GP, Boas DA, Franceschini MA, Kim YR. Validation of diffuse correlation spectroscopy measurements of rodent cerebral blood flow with simultaneous arterial spin labeling MRI; towards MRI-optical continuous cerebral metabolic monitoring. Biomed Opt Express. 2010;1:553-565.

13. Kim MN, Durduran T, Frangos $\mathrm{S}$, et al. Noninvasive measurement of cerebral blood flow and blood oxygenation using near-infrared and diffuse correlation spectroscopies in critically brain-injured adults. Neurocrit Care. 2010;12:173-180.

14. Buckley EM, Hance D, Pawlowski T, et al. Validation of diffuse correlation spectroscopic measurement of cerebral blood flow using phase-encoded velocity mapping magnetic resonance imaging. J Biomed Opt. 2012;17:037007.

15. Zhou C, Eucker SA, Durduran T, et al. Diffuse optical monitoring of hemodynamic changes in piglet brain with closed head injury. J Biomed Opt. 2009;14:034015.

16. Wilson MH, Edsell ME, Davagnanam I, et al. Caudwell Xtreme Everest Research Group. Cerebral artery dilatation maintains cerebral oxygenation at extreme altitude and in acute hypoxia - an ultrasound and MRI study. J Cereb Blood Flow Metab. 2011;31:2019-2029.

17. Hornbein TF, Townes BD, Schoene RB, Sutton JR, Houston CS. The cost to the central nervous system of climbing to extremely high altitude. $N$ Engl $\mathrm{J}$ Med. 1989;321:1714-1719.
18. Masuyama S, Kimura H, Sugita T, et al. Control of ventilation in extreme-altitude climbers. J Appl Physiol. 1986;61:500-506.

19. Oelz O, Howald H, Di Prampero PE, et al. Physiological profile of world-class high-altitude climbers. $J$ Appl Physiol. 1986;60:1734-1742.

20. Schoene RB, Lahiri S, Hackett PH, et al. Relationship of hypoxic ventilatory response to exercise performance on Mount Everest. J Appl Physiol Respir Environ Exerc Physiol. 1984;56:1478-1483.

21. West JB, Schoene RB, Milledge JS. High Altitude Medicine and Physiology. 4th ed. London: Hodder Arnold; 2007.

22. Leaf DE, Goldfarb DS. Mechanisms of action of acetazolamide in the prophylaxis and treatment of acute mountain sickness. J Appl Physiol. 2007;102:1313-1322.

23. Ehrenreich DL, Burns RA, Alman RW, Fazekas JF. Influence of acetazolamide on cerebral blood flow. Arch Neurol. 1961;5:227-232.

24. Imray $\mathrm{CH}$, Barnett $\mathrm{NJ}$, Walsh $\mathrm{S}$, et al. Near-infrared spectroscopy in the assessment of cerebral oxygenation at high altitude. Wilderness Environ Med. 1998;9:198-203.

25. Subudhi AW, Olin JT, Dimmen AC, Polaner DM, Kayser B, Roach RC. Does cerebral oxygen delivery limit incremental exercise performance? J Appl Physiol. 2011; 111:1727-1734.

26. Szczapa T, Karpiński Ł, Moczko J, et al. Comparison of cerebral tissue oxygenation values in full term and preterm newborns by the simultaneous use of two near-infrared spectroscopy devices: an absolute and a relative trending oximeter. J Biomed Opt. 2013;18:87006.

27. Pattinson KT, Imray $\mathrm{CH}$, Wright AD. What does cerebral oximetry measure? Br J Anaesth. 2005;94:863-864.

28. Heine M, Subudhi AW, Roach RC. Effect of ventilation on cerebral oxygenation during exercise: insights from canonical correlation. Respir Physiol Neurobiol. 2009;166:125-128.

29. Wilson MH, Newman S, Imray CH. The cerebral effects of ascent to high altitudes. Lancet Neurol. 2009;8:175-191.

30. Wilson $\mathrm{MH}$, Imray $\mathrm{CH}$, Hargens AR. The headache of high altitude and microgravity — similarities with clinical syndromes of cerebral venous hypertension. High Alt Med Biol. 2011;12:379-386.

31. Wilson MH, Davagnanam I, Holland G, et al. Birmingham Medical Research Expeditionary Society and Caudwell Xtreme Everest Research Group. Cerebral venous system and anatomical predisposition to high-altitude headache. Ann Neurol. 2013;73:381-389.

32. Imray $\mathrm{CH}$, Brearey $\mathrm{S}$, Clarke $\mathrm{T}$, et al. The Birmingham Medical Research Expeditionary Society. Cerebral oxygenation at high altitude and the response to carbon dioxide, hyperventilation and oxygen. Clin Sci (Lond). 2000;98:159-164.

33. Lucas SJ, Burgess KR, Thomas KN, et al. Alterations in cerebral blood flow and cerebrovascular reactivity during 14 days at 5050 m. J Physiol. 2011;589(Pt 3):741-753.

34. Querido JS, Sheel AW. Regulation of cerebral blood flow during exercise. Sports Med. 2007;37:765-782. 
35. Kety SS, Schmidt CF. The determination of cerebral blood flow in man by the use of nitrous oxide in low concentrations. Am J Physiol. 1945;143:53-66.

36. Severinghaus JW, Chiodi H, Eger EI II, Brandstater B, Hornbein TF. Cerebral blood flow in man at high altitude. Role of cerebrospinal fluid $\mathrm{pH}$ in normalization of flow in chronic hypocapnia. Circ Res. 1966;19:274-282.

37. Himwich WA, Homburger E, Maressca R, Himwich HE. Brain metabolism in man: unanesthetized and in pentothal narcosis. Am J Psychiatry. 1947;103:689-696.

38. Lichtenstein D, Saïf R, Augarde R, et al. The Internal jugular veins are asymmetric. Usefulness of ultrasound before catheterization. Intensive Care Med. 2001;27:301305.

39. Obrist WD, Thompson HK Jr, King CH, Wang HS. Determination of regional cerebral blood flow by inhalation of 133-Xenon. Circ Res. 1967;20:124-135.

40. Veall N, Mallett BL. Regional cerebral blood flow determination by $133-X e$ inhalation and external recording: the effect of arterial recirculation. Clin Sci. 1966;30:353-369.
41. Jensen JB, Wright AD, Lassen NA, et al. Cerebral blood flow in acute mountain sickness. J Appl Physiol. 1990;69: 430-433.

42. Giller CA, Bowman G, Dyer H, Mootz L, Krippner W. Cerebral arterial diameters during changes in blood pressure and carbon dioxide during craniotomy. Neurosurgery. 1993;32:737-741.

43. Serrador JM, Picot PA, Rutt BK, Shoemaker JK, Bondar RL. MRI measures of middle cerebral artery diameter in conscious humans during simulated orthostasis. Stroke. 2000;31:1672-1678.

44. Schatlo B, Gläsker S, Zauner A, Thompson BG, Oldfield EH, Pluta RM. Continuous neuromonitoring using transcranial Doppler reflects blood flow during carbon dioxide challenge in primates with global cerebral ischemia. Neurosurgery. 2009;64:1148-1154.

45. Durduran T, Yu G, Burnett MG, et al. Diffuse optical measurement of blood flow, blood oxygenation, and metabolism in a human brain during sensorimotor cortex activation. Opt Lett. 2004;29:1766-1768. 